\title{
Results of the Irradiation of R6R018 in the Advanced Test Reactor
}

\author{
A. B. Robinson \\ D. M. Wachs \\ D. D. Keiser \\ P. G. Medvedev \\ C. R. Clark \\ G. S. Chang \\ M. A. Lillo \\ J. F. Jue \\ G. A. Moore \\ J. M. Wight
}

April 2010

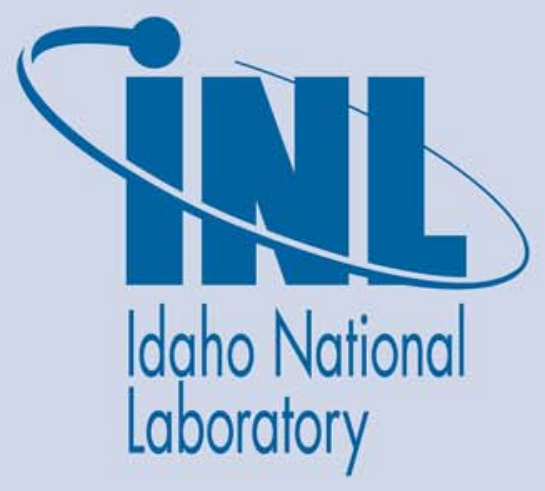

The INL is a U.S. Department of Energy National Laboratory operated by Battelle Energy Alliance 


\section{DISCLAIMER}

This information was prepared as an account of work sponsored by an agency of the U.S. Government. Neither the U.S. Government nor any agency thereof, nor any of their employees, makes any warranty, expressed or implied, or assumes any legal liability or responsibility for the accuracy, completeness, or usefulness, of any information, apparatus, product, or process disclosed, or represents that its use would not infringe privately owned rights. References herein to any specific commercial product, process, or service by trade name, trade mark, manufacturer, or otherwise, does not necessarily constitute or imply its endorsement, recommendation, or favoring by the U.S. Government or any agency thereof. The views and opinions of authors expressed herein do not necessarily state or reflect those of the U.S. Government or any agency thereof. 


\title{
Results of the Irradiation of R6R018 in the Advanced Test Reactor
}

\author{
A. B. Robinson \\ D. M. Wachs \\ D. D. Keiser \\ P. G. Medvedev \\ C. R. Clark \\ G. S. Chang \\ M. A. Lillo \\ J. F. Jue \\ G. A. Moore \\ J. M. Wight
}

April 2010

\section{Idaho National Laboratory Fuel Performance and Design \\ Idaho Falls, Idaho 83415}

http://www.inl.gov

Prepared for the

U.S. Department of Energy

Office of National Nuclear Security Administration

Under DOE Idaho Operations Office

Contract DE-AC07-05ID14517 



\section{Fuel Performance and Design}

\section{Results of the Irradiation of R6R018 in the Advanced Test Reactor}

INL/EXT-10-18074

Revision 0

April 2010

Approved by:

Adam Robinson

Date

Daniel Wachs

U.S. Technical Lead for Fuel Development

Date

Steven Hayes

Date

Manager 



\section{SUMMARY}

For over 30 years the Reduced Enrichment for Research and Test Reactors (RERTR) program has worked to provide the fuel technology and analytical support required to convert research and test reactors from nuclear fuels that utilize highly enriched uranium (HEU) to fuels based on low-enriched uranium (LEU) (defined as <20\% U-235). This effort is driven by a desire to minimize international civilian commerce in weapons-usable materials.

The RERTR fuel development program has executed a wide array of fuel tests over the last decade that clearly established the viability of research reactor fuels based on uranium-molybdenum (U-Mo) alloys. Fuel testing has included a large number of dispersion type fuels capable of providing uranium densities of up to $\sim 8.5 \mathrm{~g} \mathrm{U} / \mathrm{cc}$ ( $\sim 1.7 \mathrm{~g} \mathrm{U}-235 / \mathrm{cc}$ at $20 \%$ enrichment). The dispersion fuel designs tested are very similar to existing research test reactor fuels in that the UMo particles simply replace the current fuel phase within the matrix.

In 2003 it became evident that the first generation U-Mo-based dispersion fuel within an aluminum matrix exhibited significant fuel performance problems at high power and burn-up. These issues have been successfully addressed with a modest modification to the matrix material composition. Testing has shown that small additions of silicon (2-5 wt\%) to the aluminum (Al) matrix stabilizes the fuel performance.

The fuel plate R6R018, which was irradiated in the Advanced Test Reactor (ATR) as part of the RERTR-9B experiment, was part of an investigation into the role of the silicon content in the matrix. This plate consisted of a U-7Mo fuel phase dispersed in an Al-3.5Si matrix clad in Al-6061. This report outlines the fabrication history, the as-fabricated analysis performed prior to irradiation, the irradiation conditions, the post irradiation examination results, and an analysis of the plate's behavior. 


\section{CONTENTS}

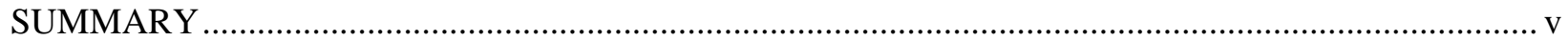

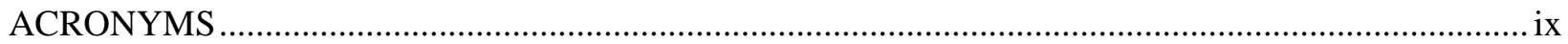

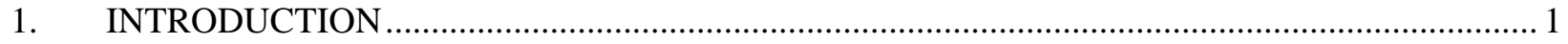

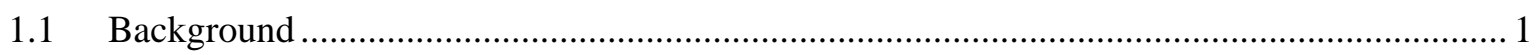

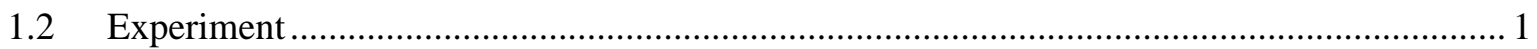

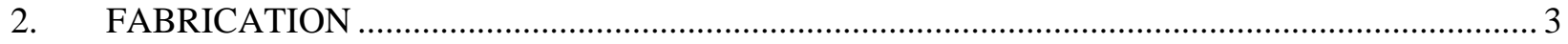

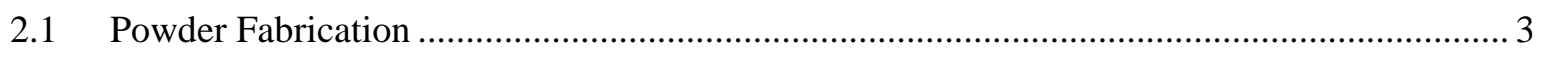

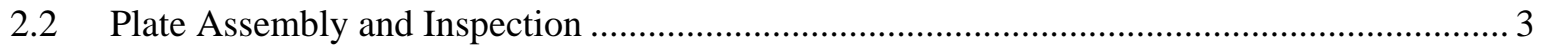

2.3 As Fabricated Characterization .............................................................................. 5

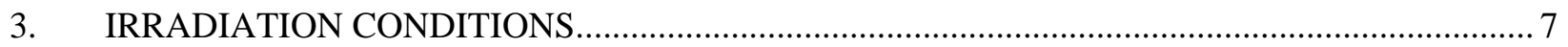

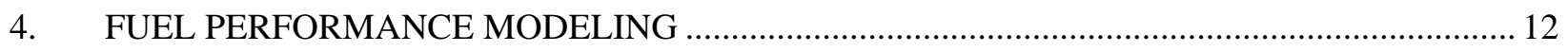

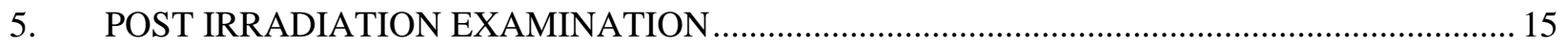

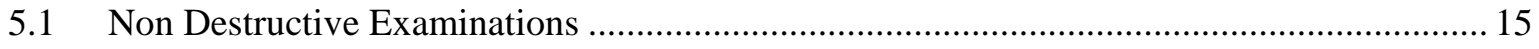

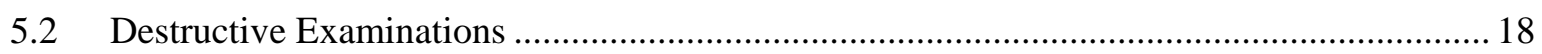

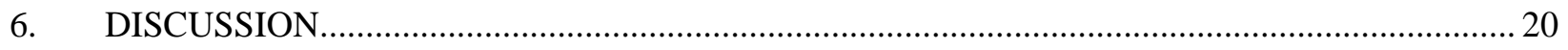

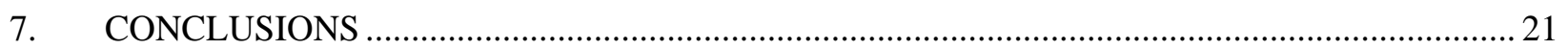

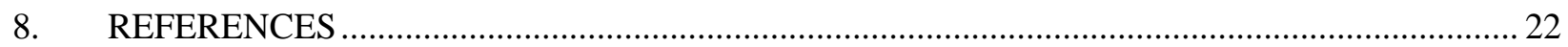

\section{FIGURES}

Figure 1. (left) Radial cross section of ATR core, (right) assembly orientation in the irradiation position.

Figure 2. Low magnification backscattered electron image of (a) the microstructure observed for the as-fabricated RERTR 9B fuel plate with Al-3.5Si alloy matrix. The fuel particles are white and the matrix is black. A higher magnification image (b) shows the narrow interaction layers (medium contrast) that were observed around the fuel particles...................... 5

Figure 3. Secondary electron image (a) and WDS ×-ray maps for (b) U, (c) Mo, (d) Al, and (e) Si.......... 6

Figure 4. Power density and burn-up plotted versus duration. .............................................................. 8

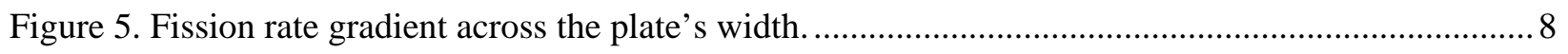

Figure 6. Fission rate gradient along the plate's length. ..................................................................... 9

Figure 7. End of cycle coolant temperatures for Cycle 140A................................................................ 10

Figure 8. End of cycle coolant temperatures for Cycle 140B............................................................... 10

Figure 9. End of cycle coolant temperatures for Cycle 141A............................................................... 11 
Figure 10. Plate thickness values as determined by PLATE code.

Figure 11. Visual examination photographs of Plate R6R018............................................................... 15

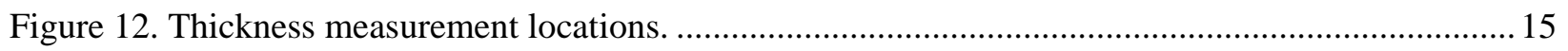

Figure 13. Post irradiation thickness measurement values. ................................................................. 16

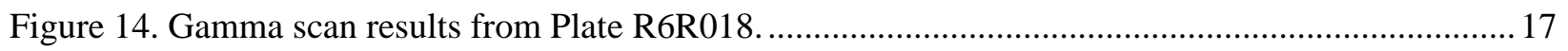

Figure 15. Plate R6R018 fuel swelling versus fission density.............................................................. 17

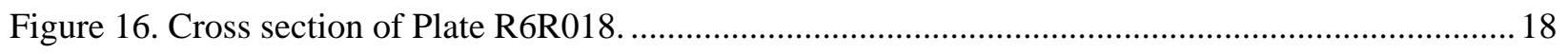

Figure 17. High magnification examination of the high power edge (left) and midpoint (right) of

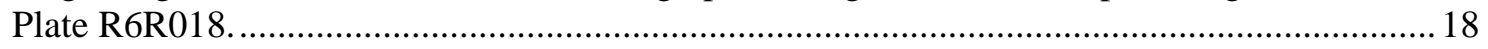

Figure 18. Metallographic images of the high power end. ................................................................... 18

Figure 19. High magnification images of the high power edge of Plate R6R018. .................................. 19

Figure 20. High magnification images of lower power edge of Plate R6R018 ...................................... 19

\section{TABLES}

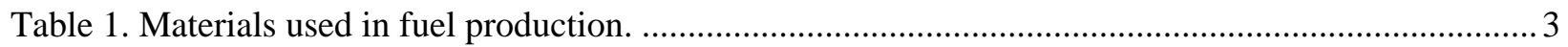

Table 2. Results of chemical analysis of final fuel powder. …............................................................... 3

Table 3. Results of chemical analysis of matrix powder. ........................................................................ 3

Table 4. Compact materials and corresponding weights. .......................................................................... 4

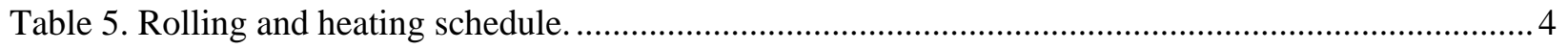

Table 6. Cycle days and power. ........................................................................................................

Table 7. Time interval distribution per cycle.......................................................................................

Table 8. Power density, heat flux, and U-235 burn-up per interval for Plate R6R018.............................. 7

Table 9. End of cycle temperature in degrees Celsius for Plate R6R018. ................................................ 9

Table 10. Calculated information for Plate R6R018 at the mid-plane as a function of location

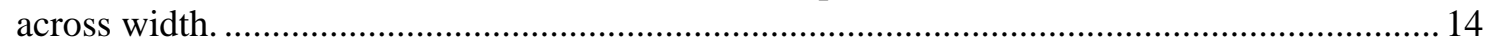

Table 11. Thickness measurement values for Plate R6R018_................................................................... 16 


\section{ACRONYMS}

$\mathrm{Al} \quad$ aluminum

ATR Advanced Test Reactor, Idaho

DOE United States Department of Energy

DU depleted uranium

EDS energy dispersive spectroscopy

EFPD effective full-power days

FASB Fuels and Applied Science Building

HEU highly enriched uranium

HFEF Hot Fuel Examination Facility

HIP hot isostatic pressing

INL Idaho National Laboratory

LEU low-enriched uranium

MCNP Monte Carlo N-Particle

MCWO Automated tool for linking Monte Carlo Transport Code with build-up code ORIGEN2

Mo molybdenum

ORIGEN2 Oak Ridge Isotope Generation and Depletion Code

PLATE Plate Lifetime Accurate Thermal Evaluation (fuel performance code)

RERTR Reduced Enrichment Research and Test Reactor

SEM scanning electron microscopy

Si silicon

U uranium

U-Mo uranium-molybdenum

WDS wavelength dispersive spectroscopy 


\section{Results of the Irradiation of R6R018 in the Advanced Test Reactor}

\section{INTRODUCTION}

\subsection{Background}

In an effort to minimize the international civilian commerce of highly enriched uranium (HEU) (defined as $>20 \%$ U-235), the RERTR program has been tasked with the development of the technology and analytical support required to convert research and test reactors to low-enriched uranium (LEU) (defined as $<20 \% \mathrm{U}-235$ ). The fuel development research associated with this program has executed a wide array of fuel tests that have shown the viability of a U-Mo based fuel phase.

U-Mo dispersion fuel tests have shown feasibility of this fuel type up to $8.5 \mathrm{~g} \mathrm{U} / \mathrm{cc}$. First generation U-Mo dispersion fuels consisted of U-Mo fuel particles dispersed in an aluminum matrix, very similar to existing research and test reactor fuels. These first generation fuel plates exhibited unacceptable fuel performance issues at high power and high burn-up. Further testing indicated that with the addition of a small amount of silicon (2-5 wt\%) into the matrix the fuel performance could be stabilized. ${ }^{1}$

\subsection{Experiment}

The purpose of the RERTR-9 experiment was to investigate the effects of modifications to the previously tested U-Mo based fuels. The primary focus was to enhance the understanding of how fuel behavior is affected by fission rates, temperature, fission density, slight composition shifts, and fuel density loading.

The RERTR-9 experiment consisted of four capsules (A-D), each containing eight plates. The plates are arranged in two rows of four in each capsule. ${ }^{2}$ Each plate is nominally 1 inch in width, 4 inches in height, and 0.055 inches in thickness. While the goal of the RERTR program is to develop LEU fuels, the size of the mini-plates requires the use of HEU fuel in order to test prototypic conditions including power density and temperature. The RERTR-9 experiment was irradiated in the B-11 position of the Advanced Test Reactor (ATR) with the capsule oriented such that one edge of the plates is facing the core center (Figure 1). The orientation combined with the higher enrichment leads to self shielding and a subsequent large fission density gradient across the 1-inch width of the plate.

Plate R6R018 was located in the B-7 position of the RERTR-9 experiment. It was comprised of U7wt\%Mo fuel particles dispersed in an Al-3.5wt\%Si matrix and clad with Al-6061. It was irradiated for 115 effective full power days (EFPD) in the ATR. After irradiation the experiment was transferred to the Hot Fuel Examination Facility (HFEF) for post irradiation examination. 


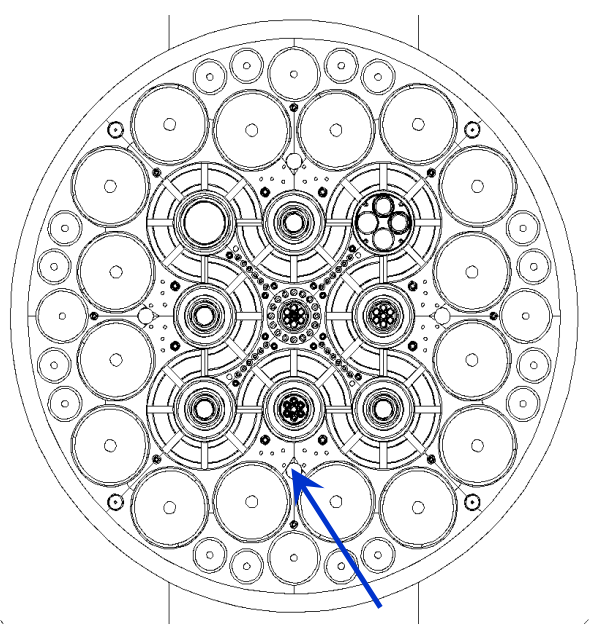

\section{(Core Center)}

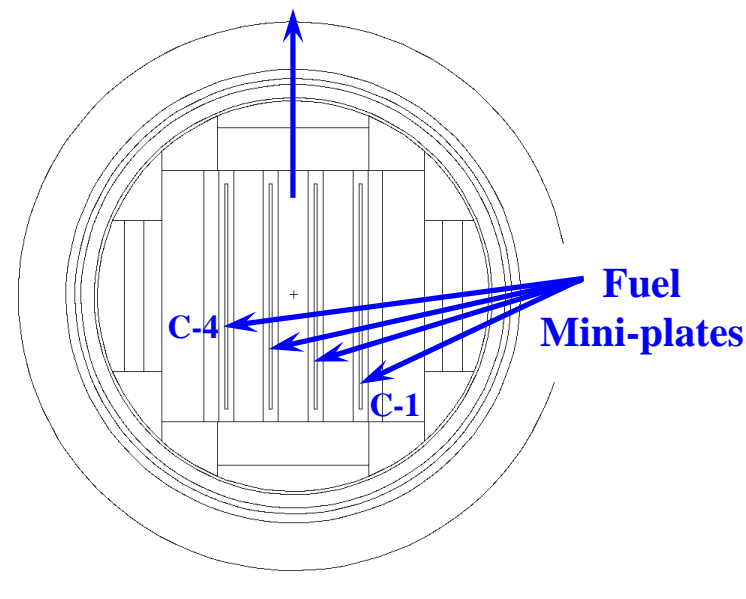

B-11

Figure 1. (left) Radial cross section of ATR core, (right) assembly orientation in the irradiation position. 


\section{FABRICATION}

This report includes the fabrication history of the R6R018 plate, as this affects the chemical diffusion and starting microstructure, which in turn will affect the fuel performance behavior during irradiation. This plate was fabricated in the Fuels and Applied Science Building (FASB) at Idaho National Laboratory (INL).

\subsection{Powder Fabrication}

The fuel was produced using a blend of HEU, depleted uranium (DU), and molybdenum (Table 1). The materials were blended using an arc-melting furnace with multiple melts and ingot flips to ensure homogenization of the alloy blend. A total of three buttons were produced of the same (nominally) alloy and uranium enrichment. Each of the three buttons was cast into pins for atomization.

Table 1. Materials used in fuel production.

\begin{tabular}{lcc}
\hline \multicolumn{1}{c}{ Material } & Purity (\%) & Enrichment $\left(\% \mathrm{U}^{235}\right)$ \\
\hline HEU & 99.74 & 93.17 \\
DU & 99.8 & 0.20 \\
Molybdenum & 99.95 & N/A \\
\hline
\end{tabular}

Atomization of the powder was conducted using a standard rotating electrode process atomizer in an inert atmosphere glovebox. The oversize material $(>106 \mu \mathrm{m})$ was recycled along with stub portions of the cast pins by remelting into buttons and casting into pins. This process and characterization is detailed in a previously published paper. ${ }^{3}$ Chemical analysis was performed on several grab samples of the final powder and the results can be seen in Table 2 .

Table 2. Results of chemical analysis of final fuel powder.

\begin{tabular}{lc}
\hline \multicolumn{1}{c}{ Item } & Amount (wt.\%) \\
\hline Molybdenum & 6.99 \\
Total Uranium & 93.01 \\
$\mathrm{U}^{235}$ (of Total U) & 58.14 \\
\hline
\end{tabular}

Aluminum matrix material used in Plate R6R018 consisted of an alloyed binary material gas atomized to produce a powder. This powder had a nominal composition of 3.5\% Si. This material was vacuum degassed prior to compaction according to a standard procedure. Final chemical analysis for this material is shown in Table 3.

Table 3. Results of chemical analysis of matrix powder.

\begin{tabular}{cccccc}
\hline Element & Amount & Element & Amount & Element & Amount \\
\hline $\mathrm{Si}$ & 3.41 & $\mathrm{Fe}$ & 0.08 & $\mathrm{Cu}$ & $<0.01$ \\
$\mathrm{Mn}$ & $<0.01$ & $\mathrm{Mg}$ & 0.001 & $\mathrm{Cr}$ & $<0.01$ \\
$\mathrm{Ni}$ & $<0.01$ & $\mathrm{Zn}$ & $<0.01$ & $\mathrm{Ti}$ & $<0.01$ \\
$\mathrm{Sn}$ & $<0.01$ & $\mathrm{~Pb}$ & $<0.01$ & $\mathrm{Al}$ & Remainder \\
\hline
\end{tabular}

\subsection{Plate Assembly and Inspection}

Fuel meat compacts were fabricated in an inert atmosphere glovebox. The fuel and matrix powders were blended in a glass vial by hand shaking for two minutes. The blended powder was poured into a die 
measuring $17.75 \mathrm{~mm}$ by $22.25 \mathrm{~mm}$. Prior to loading the powder, the die was lubricated with a thin coat of aerosol zinc stearate. The die was compacted in a hydraulic press to $213.5 \mathrm{kN}$ and the pellet was removed from the die, crushed with a mortar and pestle, and then recompacted as before to render the final pellet. Thickness of this pellet was measured as $0.2 \mathrm{~cm}$. The compact masses are shown in Table 4.

Table 4. Compact materials and corresponding weights.

\begin{tabular}{lcc}
\hline & \multicolumn{2}{c}{ Powder Mass (g) } \\
\cline { 2 - 3 } \multicolumn{1}{c}{ Material } & Starting & Final (Calculated) \\
\hline Matrix (Al-3.5Si) & 0.921 & 0.916 \\
Small Fuel Alloy $(<90 \mu \mathrm{m})$ & 5.540 & 5.510 \\
Large Fuel Alloy $(90-106 \mu \mathrm{m})$ & 0.978 & 0.973 \\
\hline
\end{tabular}

The cladding plate hardware consisted of two aluminum 6061 sheet stock. A thin cover plate and a thicker plate with a machined recess sized to fit the fuel compact. The sheets were sized so that the assembled pellet was midway between the two faces of the rolling assembly. The cladding was cleaned using a wire brush to remove any gross scale from the plates followed by a degreasing (acetone and ethanol), sodium hydroxide and nitric acid, and assorted rinses. The fuel compacts were loaded into the aluminum hardware within 1 day of cleaning. The assembly was then welded closed for rolling.

The plates were rolled using a large two-high rolling mill in conjunction with a plate-heating furnace. Rolling takes place within 1 day of the assembly/welding. The rolling schedule/heating times are identified in Table 5. This rolling schedule has been shown to deliver plates at the desired thickness $(0.055 \pm 0.002$ in $)$.

Table 5. Rolling and heating schedule.

\begin{tabular}{cccccc}
\hline \multirow{2}{*}{$\begin{array}{c}\text { Pass } \\
\text { No. }\end{array}$} & Thickness (in.) & & \multicolumn{3}{c}{ Heating Soak } \\
\cline { 4 - 6 } & Target & Reduction & Time & Total & Temp \\
\hline 0 & 0.222 & $0 \%$ & 20 & 20 & 500 \\
1 & 0.189 & $15 \%$ & 10 & 30 & 500 \\
2 & 0.160 & $15 \%$ & 10 & 40 & 500 \\
3 & 0.128 & $20 \%$ & 10 & 50 & 500 \\
4 & 0.103 & $20 \%$ & 10 & 60 & 500 \\
5 & 0.082 & $20 \%$ & 5 & 65 & 500 \\
6 & 0.066 & $20 \%$ & 5 & 70 & 500 \\
7 & 0.066 & $0 \%$ & 5 & 75 & 500 \\
\hline
\end{tabular}

After final rolling the furnace was cooled to $485^{\circ} \mathrm{C}$, the plate was placed inside the furnace, and heated for 30 minutes. After the heating step the plate was removed from the furnace, cooled in air, and examined for blisters. Plate R6R018 passed the blister inspection with no comment.

The rolled plate then underwent radiography to determine the location of the fuel zone within the plate and to determine if there is excessive fuel out of zone. Using the radiography and an overlay template the plates were marked and sheared to their final size. After shearing to their final size the plates were sent again to radiography to determine fuel location, fuel out of zone, and fuel density. Plate R6R018 passed the radiography inspection with no comment. 


\subsection{As Fabricated Characterization}

Characterization using scanning electron microscopy (SEM) with energy dispersive and wavelength dispersive spectroscopy (EDS/WDS) was performed on an archive fuel plate (R6R038) that was fabricated using the same U-7Mo and Al-3.5\%Si powders and the same fabrication parameters as were used to fabricate Plate R6R018. A cross section of the fuel plate was first mounted in epoxy, polished through 1200-grit sandpaper, and coated with Pd before being inserted into the SEM for analysis. Secondary electron and backscattered electron images were taken to determine the fuel plate microstructure, EDS and WDS $\times$-ray mapping was employed to determine the partitioning behavior of the various components, and point-to-point EDS compositional analysis was performed to determine phase compositions in the thickest interaction layer regions.

Figure 2 shows low and high magnification backscattered electron images of the microstructure observed for fuel plate R6R038. A thin fuel/matrix interaction layer was observed around the fuel particles. WDS $\times$-ray maps were produced for $\mathrm{U}, \mathrm{Mo}, \mathrm{Al}$, and $\mathrm{Si}$ in different areas of the microstructure, and these maps (Figure 3) confirmed that the interaction layers were enriched in Si. Si is also present in Si-rich precipitates in the Al-3.5Si matrix. Point-to-point EDS analysis was performed in the thickest interaction layer regions. It was determined that the interaction layer was up to $5 \mu \mathrm{m}$ thick, and the $\mathrm{Si}$ content varied between 5 and 30 at.\% Si.
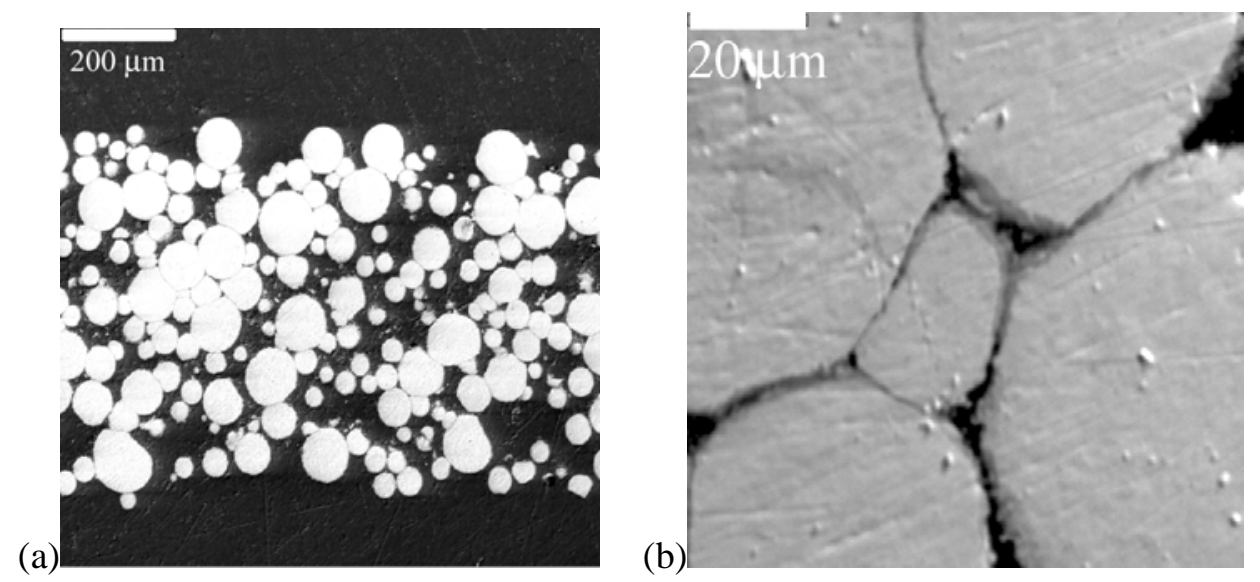

Figure 2. Low magnification backscattered electron image of (a) the microstructure observed for the as-fabricated RERTR 9B fuel plate with Al-3.5Si alloy matrix. The fuel particles are white and the matrix is black. A higher magnification image (b) shows the narrow interaction layers (medium contrast) that were observed around the fuel particles. 


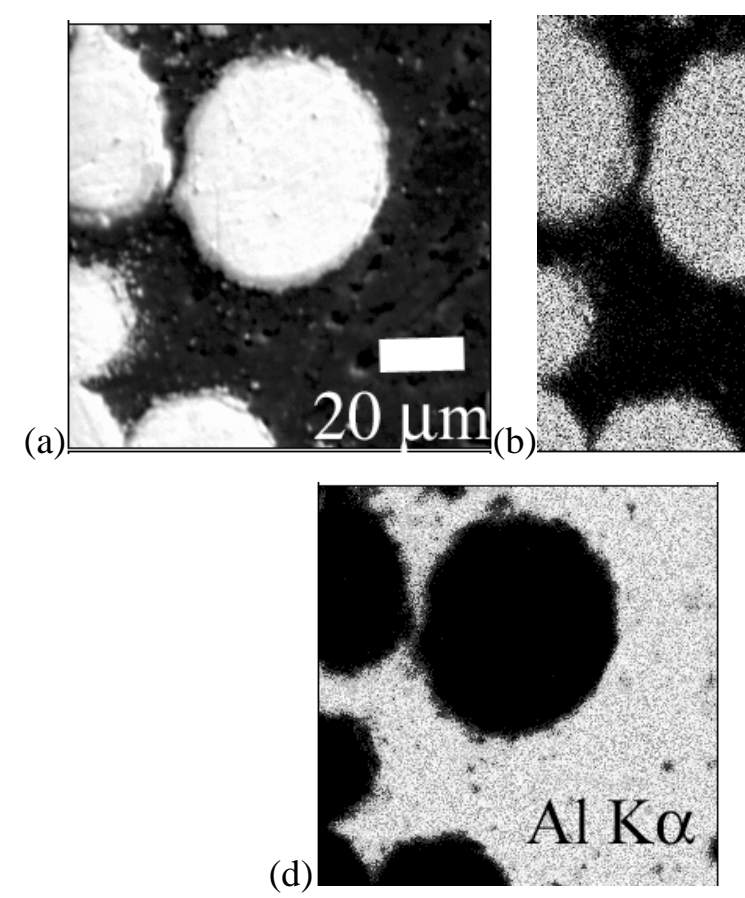

\section{$\mathrm{U} \mathrm{M} \alpha$}

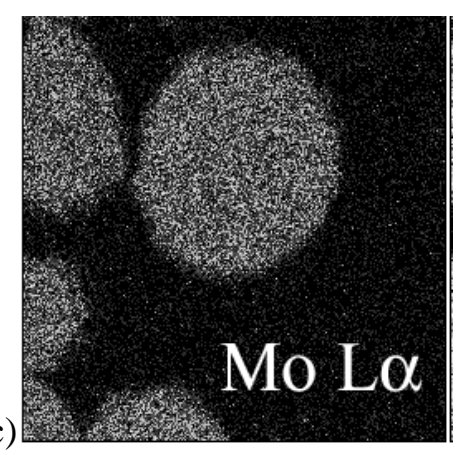

(e)

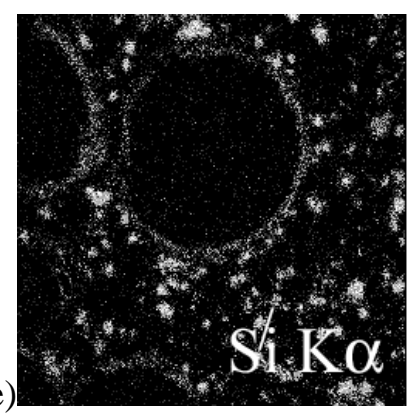

Figure 3. Secondary electron image (a) and WDS ×-ray maps for (b) U, (c) Mo, (d) Al, and (e) Si. 


\section{IRRADIATION CONDITIONS}

Plate R6R018 was irradiated during cycles 140A, 140B, and 141A. These experiments were irradiated in the large-B position B-11. The power of this position in the core is represented by the south lobe power, which is the average of the $\mathrm{SW}, \mathrm{C}$, and $\mathrm{SE}$ lobe powers, $\mathrm{S}=(\mathrm{SW}+\mathrm{C}+\mathrm{SE}) / 3$. The irradiation days and power are shown in Table 6.

Table 6. Cycle days and power.

\begin{tabular}{|c|c|c|c|c|c|c|c|}
\hline $\begin{array}{l}\text { ATR } \\
\text { Cycle }\end{array}$ & $\begin{array}{c}\text { RERTR-9A/B } \\
\text { Test ID } \\
\end{array}$ & $\begin{array}{l}\text { RERTR-9 } \\
\text { Capsules } \\
\text { Irradiated }\end{array}$ & Dates Irradiated & $\begin{array}{l}\text { Cycle } \\
\text { EFPDs }\end{array}$ & $\begin{array}{c}\text { Mid-Cycle } \\
\text { Scram } \\
\text { Decay } \\
\text { Days } \\
\end{array}$ & $\begin{array}{c}\text { Post-Cycle } \\
\text { Decay } \\
\text { Days }\end{array}$ & $\begin{array}{c}\text { South } \\
\text { Lobe } \\
\text { Source } \\
\text { Power } \\
\text { (MW) }\end{array}$ \\
\hline $140 \mathrm{~A}$ & RERTR-9A/B & A,B,C,D & $\begin{array}{c}10 / 16 / 2007- \\
12 / 01 / 2007\end{array}$ & 46.5 & - & 15 & 22.6 \\
\hline 140B & RERTR-9B & B,D & $\begin{array}{l}\text { 12/16/2007- } \\
01 / 26 / 2008\end{array}$ & 35.7 & 8 & 10 & 22.8 \\
\hline $141 \mathrm{~A}$ & RERTR-9B & B,D & $\begin{array}{c}02 / 05 / 2008- \\
03 / 06 / 2008\end{array}$ & 32.4 & - & 55 & 23.1 \\
\hline
\end{tabular}

Three computer codes (Monte Carlo N-Particle [MCNP], MCWO, and ORIGEN2) were used to calculate the as-run fuel fission neutron heat rates, power density, and U-235 burn-up. The plate average power and burn-up were calculated for five time intervals per cycle with intervals 2-4 being of most relevance (Table 7). The fission power density, heat flux, and burn-up calculated for Plate R6R018 for the indicated time intervals can be seen in Table 8 and graphically in Figure 4.

Table 7. Time interval distribution per cycle.

\begin{tabular}{cccc}
\hline $\begin{array}{c}\text { Time } \\
\text { Interval }\end{array}$ & $\begin{array}{c}140 \mathrm{~A} \\
\text { (days) }\end{array}$ & $\begin{array}{c}140 \mathrm{~B} \\
\text { (days) }\end{array}$ & $\begin{array}{c}141 \mathrm{~A} \\
\text { (days) }\end{array}$ \\
\hline 01 & $1.00 \mathrm{E}-4$ & $1.00 \mathrm{E}-4$ & $1.00 \mathrm{E}-4$ \\
02 & 18 & 12 & 15 \\
03 & 18 & 12 & 10 \\
04 & 10.5 & 11 & 7 \\
05 & $1.00 \mathrm{E}-3$ & $1.00 \mathrm{E}-3$ & $1.00 \mathrm{E}-3$ \\
EFPDs & 46.50 & 35.00 & 32.00 \\
\hline
\end{tabular}

Table 8. Power density, heat flux, and U-235 burn-up per interval for Plate R6R018.

\begin{tabular}{|l|c|c|c|}
\hline Cycle/Interval & $\begin{array}{c}\text { Fission Power } \\
\text { Density (W/cc) }\end{array}$ & $\begin{array}{c}\text { Heat Flux } \\
\left(\mathrm{W} / \mathrm{cm}^{2}\right)\end{array}$ & $\begin{array}{c}\text { Cumulative U-235 } \\
\text { Burn-up U-235/U-235 }\end{array}$ \\
initial \\
Cycle 140A/02 & 11414.60 & 289.93 & $5.88 \%$ \\
\hline Cycle 140A/03 & 10250.11 & 260.35 & $11.25 \%$ \\
\hline Cycle 140A/04 & 10949.42 & 278.12 & $14.32 \%$ \\
\hline Cycle 140B/02 & 9559.97 & 242.82 & $17.65 \%$ \\
\hline Cycle 140B/03 & 10790.47 & 274.08 & $21.34 \%$ \\
\hline Cycle 140B/04 & 10686.13 & 271.43 & $25.14 \%$ \\
\hline Cycle 141A/02 & 9711.84 & 246.68 & $29.40 \%$ \\
\hline Cycle 141A/03 & 9373.52 & 238.08 & $32.12 \%$ \\
\hline
\end{tabular}




\begin{tabular}{|l|l|l|l|}
\hline Cycle 141A/04 & 10232.18 & 259.90 & $34.02 \%$ \\
\hline
\end{tabular}

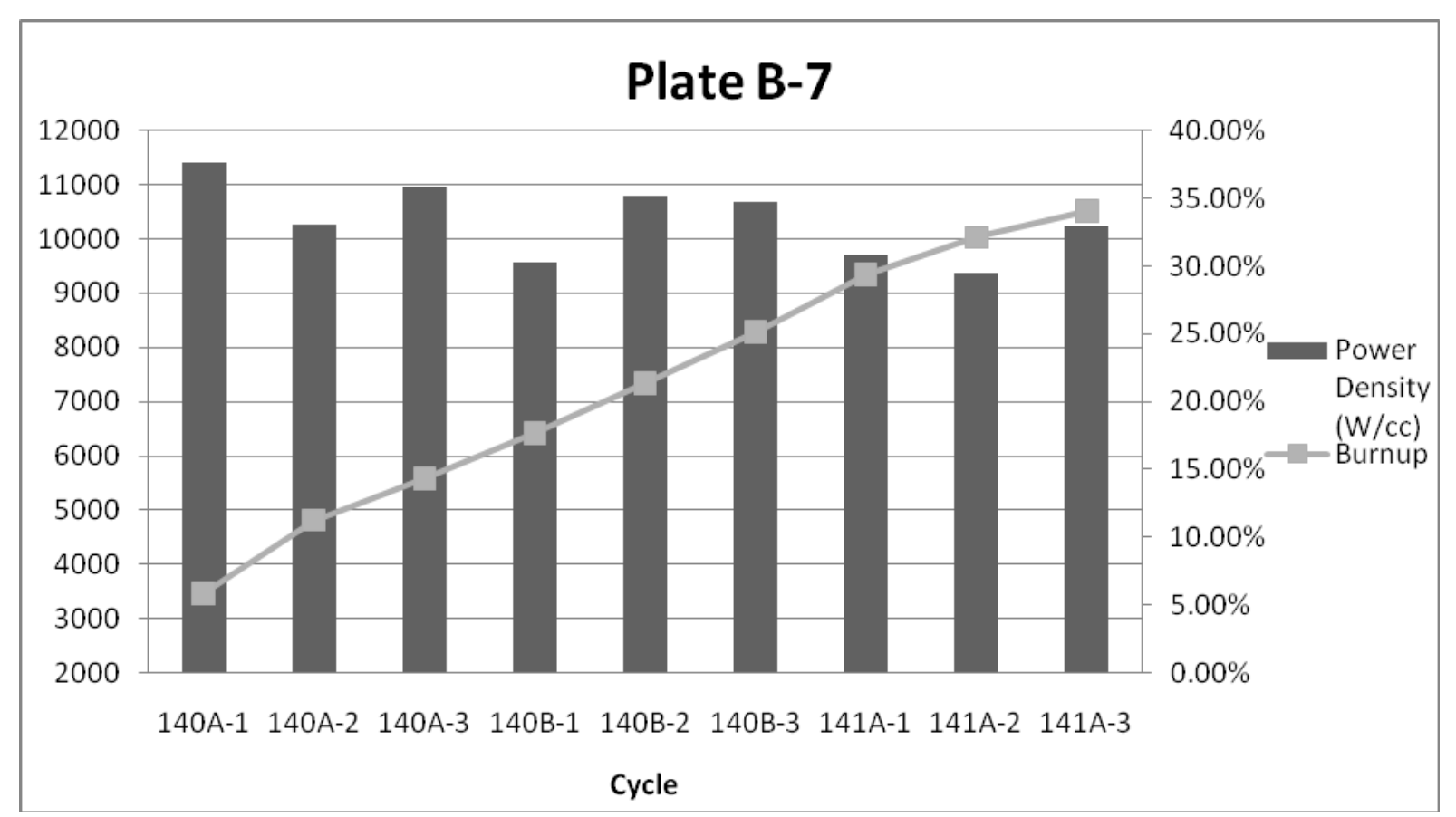

Figure 4. Power density and burn-up plotted versus duration.

As shown in Figure 1, the alignment of the plates is such that a large fission density gradient exists across the width of the fuel plates. Also, spacing between the plates in the length direction allows for extra moderator, and therefore peaking at the ends of the plates. Fission rate gradients are calculated using end of irradiation depletion values, and therefore do not take into account localized depletion during the irradiation. The calculated gradients can be seen in Figure 5 and Figure 6 for the transverse and longitudinal directions, respectively.

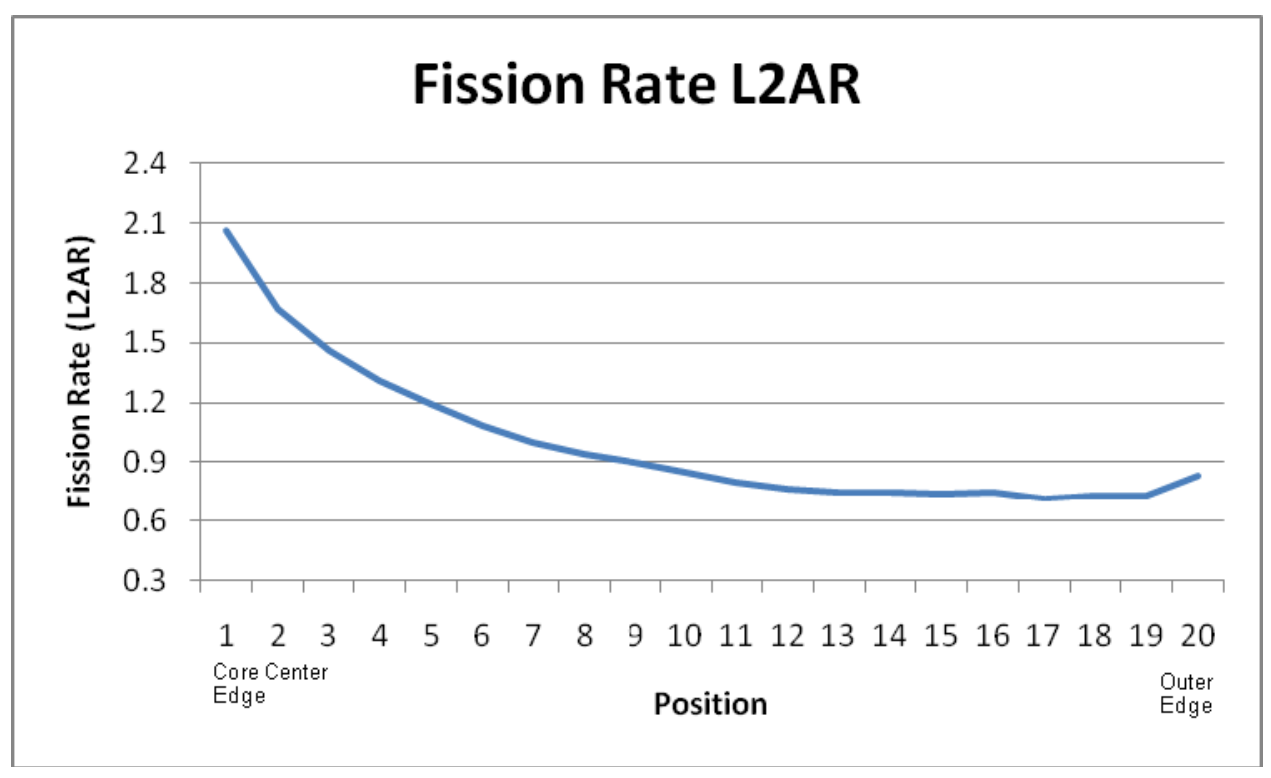

Figure 5. Fission rate gradient across the plate’s width. 


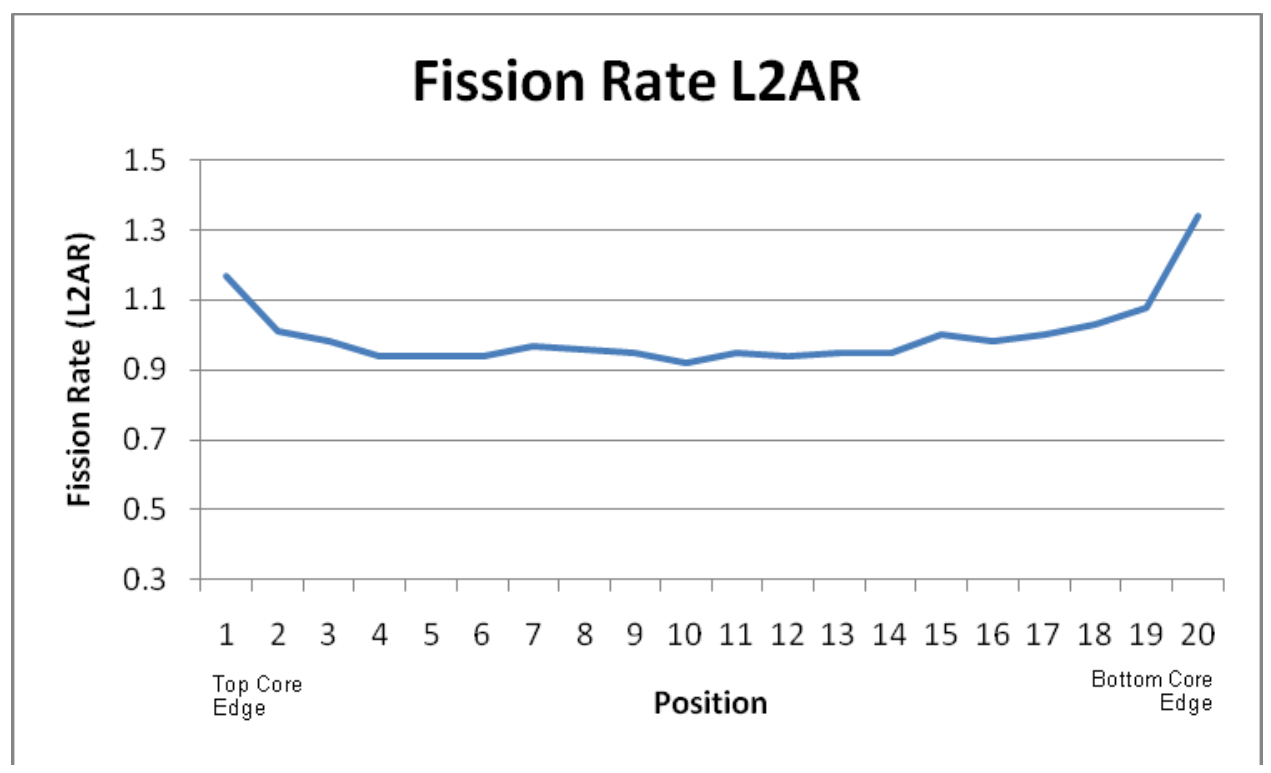

Figure 6. Fission rate gradient along the plate’s length.

Plate surface temperatures were calculated for the end of each irradiation cycle. For Plate R6R018, the maximum, minimum, and average plate surface temperature at the end of each cycle is given in Table 9. The temperatures for the entire irradiation assembly can be seen in Figure 7, Figure 8, and Figure 9 with Plate R6R018 located in between Channels 3 and 4 and roughly 12-16 inches from top of assembly.

Table 9. End of cycle temperature in degrees Celsius for Plate R6R018.

\begin{tabular}{llll} 
& $140 \mathrm{~A}$ & $140 \mathrm{~B}$ & $141 \mathrm{~A}$ \\
\hline Maximum & 103.7 & 99.8 & 98.0 \\
Minimum & 59.5 & 56.4 & 56.3 \\
Average & 82.3 & 79.0 & 78.0 \\
\hline
\end{tabular}




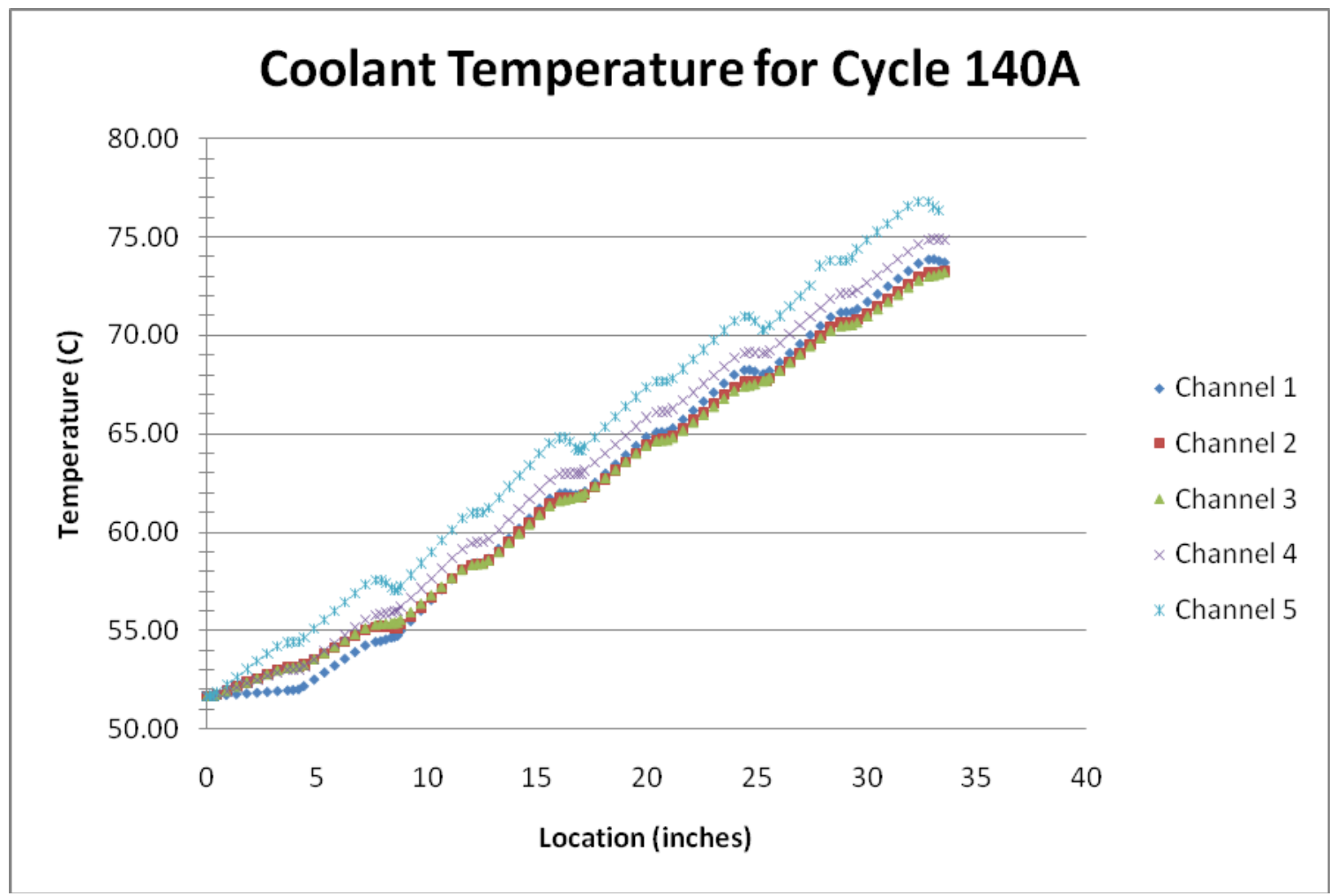

Figure 7. End of cycle coolant temperatures for Cycle 140A.

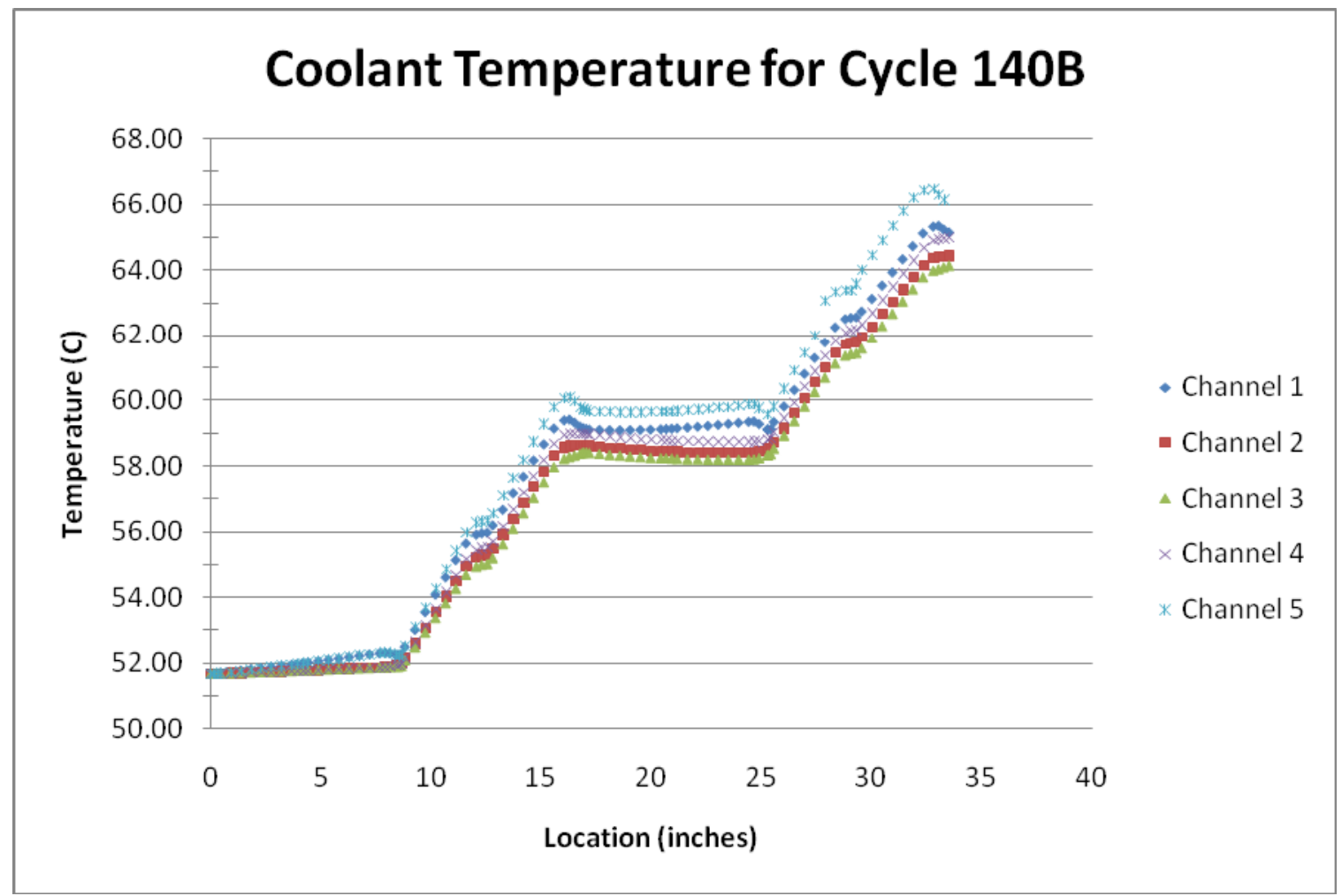

Figure 8. End of cycle coolant temperatures for Cycle 140B. 


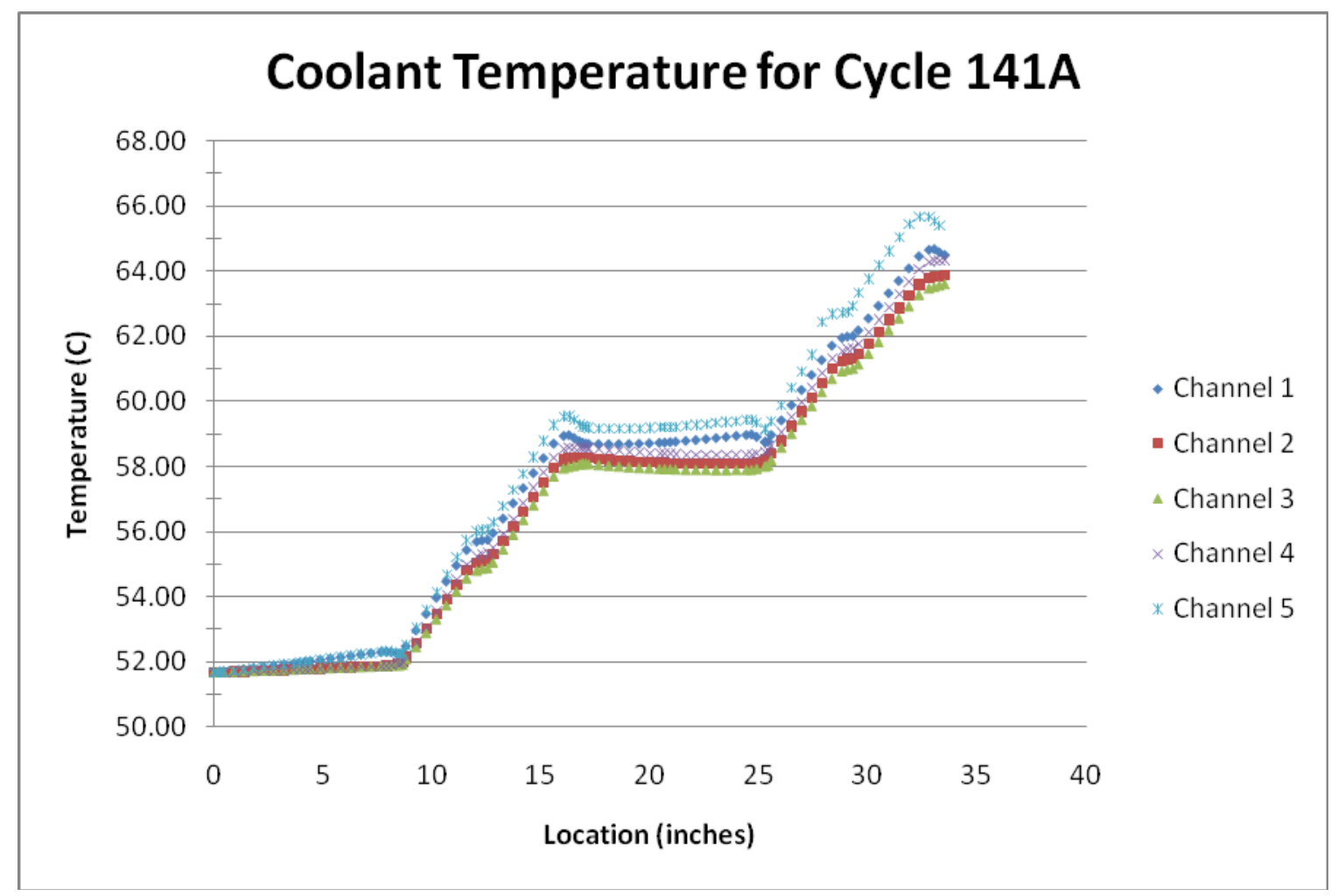

Figure 9. End of cycle coolant temperatures for Cycle 141A. 


\section{FUEL PERFORMANCE MODELING}

Local performance metrics were calculated using Plate Lifetime Accurate Thermal Evaluation (PLATE) fuel performance code. ${ }^{4}$ The following empirical behavior models were used in this analysis. Swelling due to fission products was calculated as a sum of swelling due to fission gas and swelling due to solid fission products as a function of fission density ${ }^{5}$ :

Equation 1 shows fuel swelling due to fission gas at low fission density.

$$
\left(\frac{\Delta V}{V_{0}}\right)_{g}=1.8 \times 10^{-21}\left(f_{d}\right), \text { for } f_{d} \leq 3 \times 10^{21} \mathrm{f} / \mathrm{cm}^{3} \text {, }
$$

Equation 2 shows fuel swelling due to fission gas at high fission density.

$$
\left(\frac{\Delta V}{V_{0}}\right)_{g}=5.4+2.2 \times 10^{-21}\left(f_{d}-3 \times 10^{21}\right)+0.51 \times 10^{-42}\left(f_{d}-3 \times 10^{21}\right)^{2}, \quad \text { for } 3 \times 10^{21} \leq f_{d} \text {. }
$$

Equation 3 shows fuel swelling due to solid fission products.

$\left(\frac{\Delta V}{V_{0}}\right)_{s}=3.5 \times 10^{-21} f_{d}$

The interaction layer growth was calculated using the following power law ${ }^{6}$ :

Equation 4 shows the interaction layer growth as a function of the labeled variables.

$$
\mathrm{Y}^{2}=\mathrm{A} \mathrm{F}_{\mathrm{r}}^{0.5} \exp \left(-\frac{\mathrm{Q}}{\mathrm{RT}}\right) \mathrm{t}
$$

where:

$$
\begin{aligned}
& \mathrm{Y}=\mathrm{IL} \text { thickness }(\mathrm{cm}) \\
& \mathrm{A}=7.5 \times 10^{-18} \text {, pre-exponential factor } \\
& \mathrm{Fr}=\text { fission rate }(\mathrm{f} / \mathrm{cm} 3-\mathrm{s}) \\
& \mathrm{T}=\text { temperature }(\mathrm{K}) \\
& \mathrm{t}=\text { time }(\mathrm{s}) \\
& \mathrm{Q}=8000(\mathrm{cal} / \mathrm{mol}) \text {, activation energy. }
\end{aligned}
$$

Calculated parameters included heat flux, peak temperature, temperature profile, fuel particle swelling, interaction layer thickness, plate thickness swelling, and corrosion layer thickness. The calculations were based on the nominal dispersion fuel plate design, plate as-built data, and the power history calculated by Chang et al. ${ }^{7},{ }^{8}$ Detailed calculations were done at the location where the plate would be sectioned for metallography to verify results. They can be seen in Table 10. Figure 10 shows the predicted plate thickness values as determined by the PLATE code. 


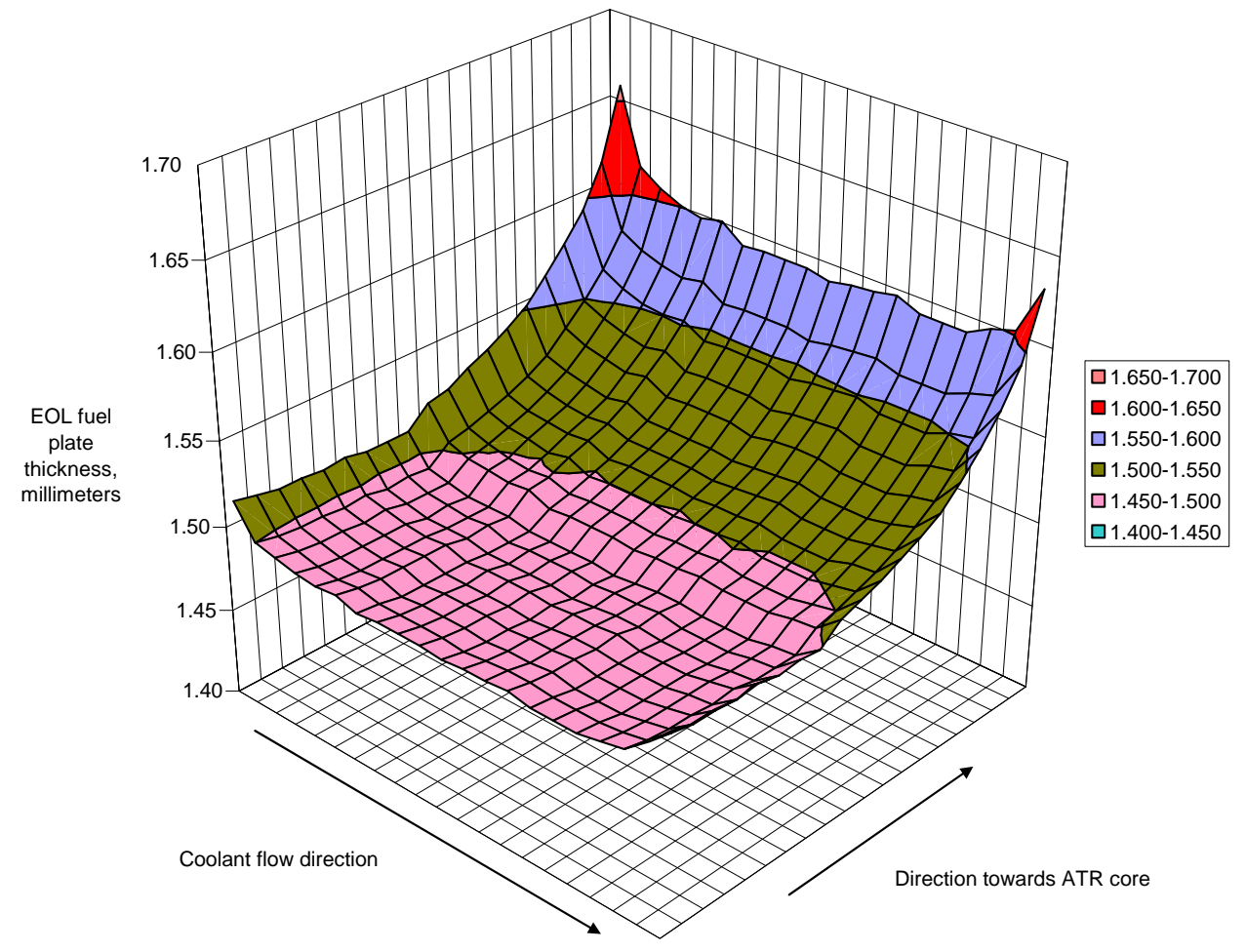

Figure 10. Plate thickness values as determined by PLATE code. 
Table 10. Calculated information for Plate R6R018 at the mid-plane as a function of location across width.

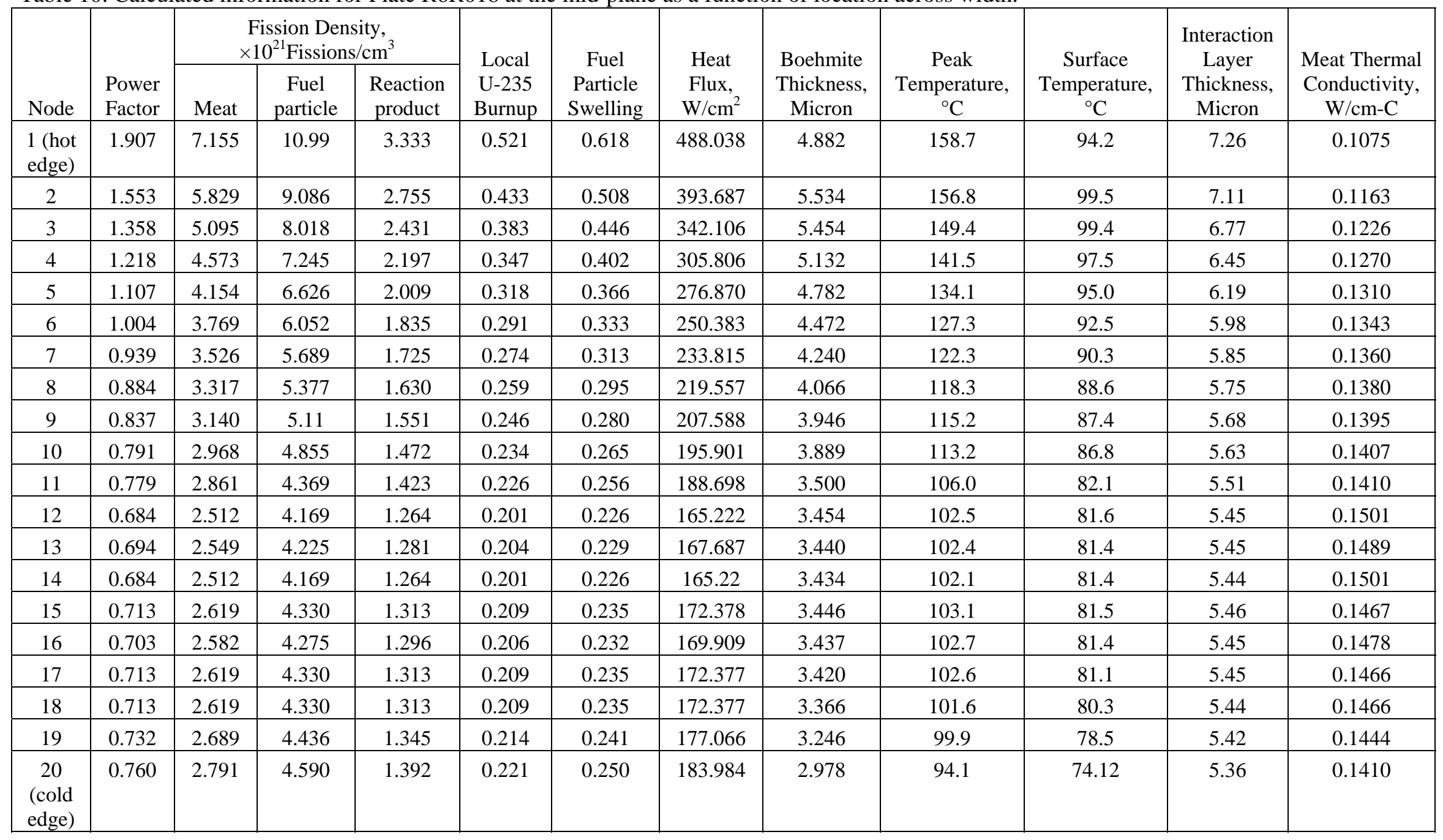




\section{POST IRRADIATION EXAMINATION}

Following irradiation, the RERTR-9 experiment was shipped to the HFEF at INL. Post irradiation examination of Plate R6R018 consisted of visual examination, gamma scanning, profilometry, eddy current testing, and metallography.

\subsection{Non Destructive Examinations}

Visual examination of the plate after removal from the irradiation capsule showed no signs of excessive swelling or oxidation, blistering, or gross deformation. Figure 11 shows the photographs taken of both the front (left) and back (right) of the plate during the examination. The lighter colored region of the plate over the fuel indicates a boehmite oxide layer indicative of a higher temperature during irradiation. Eddy current testing was done on 15 plates in the experiment to investigate the oxide thickness formation on the plate. The peak oxide observed was $21 \mu \mathrm{m}$ with the average thickness being $3.6 \mu \mathrm{m}$.

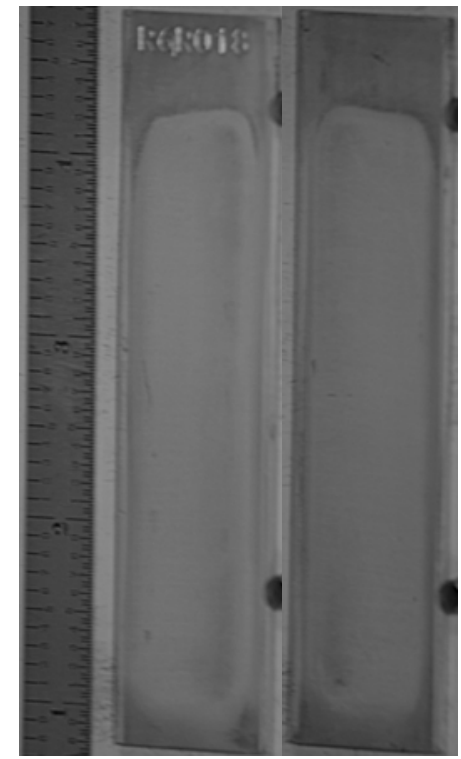

Figure 11. Visual examination photographs of Plate R6R018.

Plate thickness measurements were performed during post irradiation to determine swelling of the fuel. Measurements were taken at 18 locations on the plate with three locations being on the bottom rail outside of the fuel zone (Figure 12). These measurement results, as well as the pre-irradiation thickness measurement values can be seen in Table 11. The post irradiation thickness values are plotted in Figure 13 and compare very well with the values predicted by the fuel performance modeling previously shown.

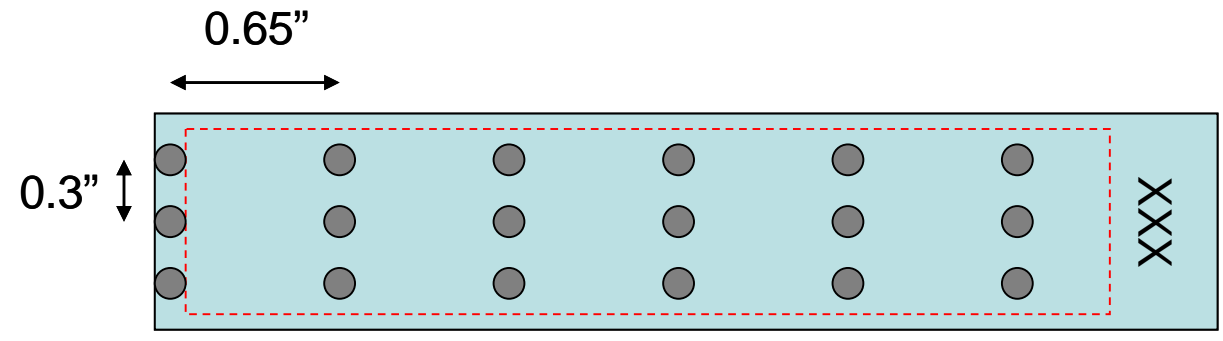

Left

Middle

Right

Figure 12. Thickness measurement locations. 
Table 11. Thickness measurement values for Plate R6R018.

\begin{tabular}{lllllll}
\hline \multicolumn{7}{c}{ Post Irradiation } \\
\hline Left & 1.447 & 1.542 & 1.511 & 1.492 & 1.518 & 1.550 \\
Middle & 1.431 & 1.555 & 1.511 & 1.506 & 1.509 & 1.559 \\
Right & 1.422 & 1.686 & 1.594 & 1.607 & 1.591 & 1.687 \\
\hline \multicolumn{7}{c}{ Pre Irradiation } \\
\hline Left & 1.43002 & 1.4351 & 1.41478 & 1.41478 & 1.4224 & 1.40462 \\
Right & 1.4224 & 1.42748 & 1.41986 & 1.4224 & 1.41732 & 1.41478 \\
\hline
\end{tabular}

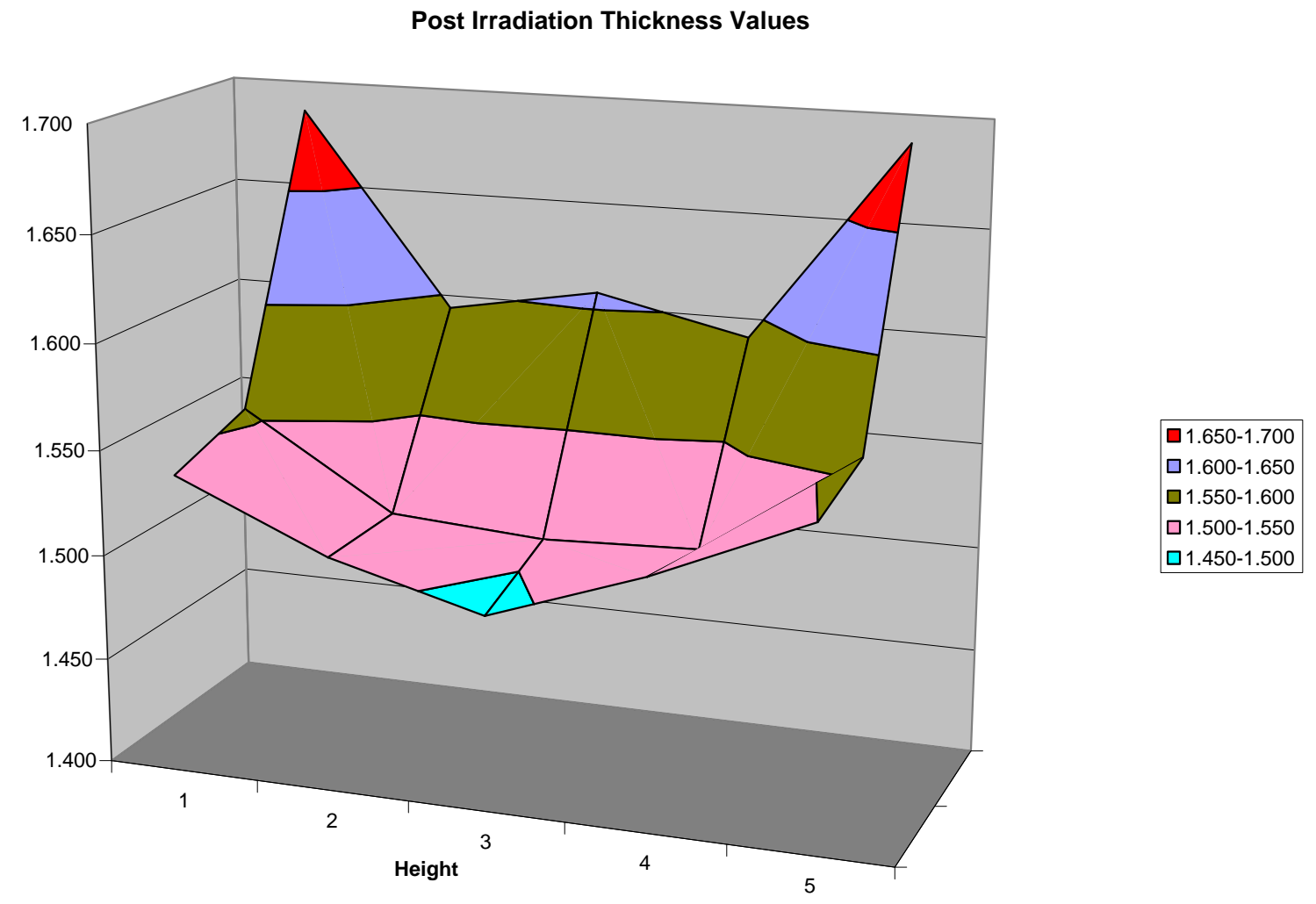

Figure 13. Post irradiation thickness measurement values.

Gamma scanning of the plate was done to verify gradient calculations and burn-up information. Gamma scans are performed in both the axial and transverse direction of the plate. Plots of the gamma scan profiles collected can be seen in Figure 14. The high power to low power edge ratio for the transverse gamma scan is approximately 2.4 while the top to bottom ratio for the axial scan is approximately 1.08. This agrees with the gradient calculations shown in Figure 5 and Figure 6, which show ratios of approximately 2.5 and 1.1 for the transverse and axial gradients, respectively. 
R6R018 Axial Gamma Scan

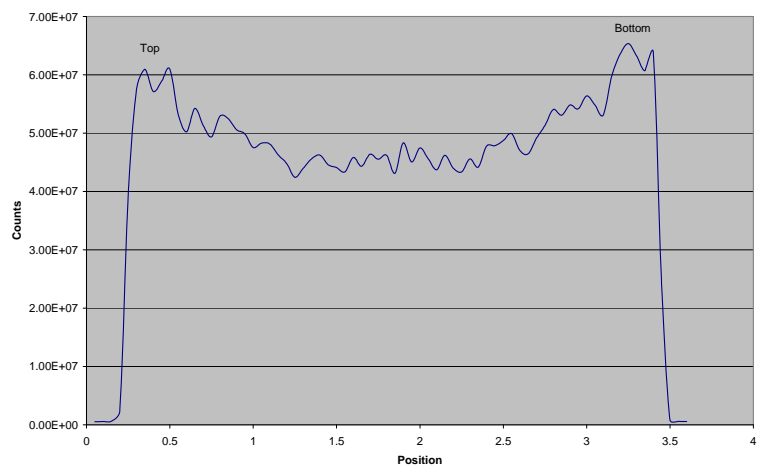

R6R018 Transverse Gamma Scan

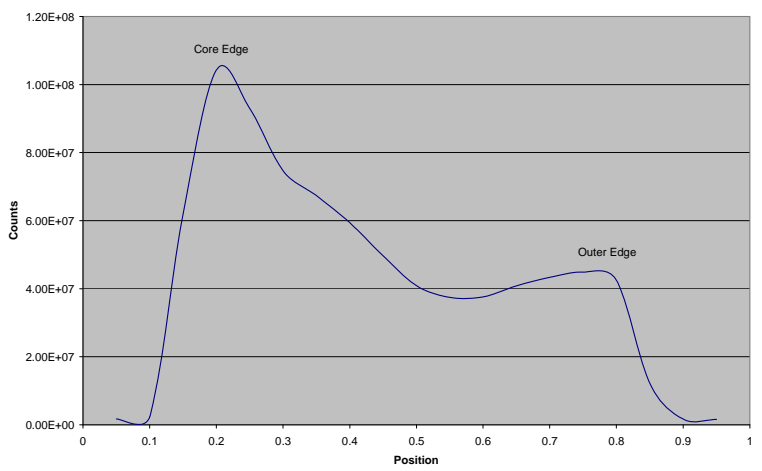

Figure 14. Gamma scan results from Plate R6R018.

Swelling calculations show a peak plate swelling of $16 \%$ and average plate swelling of $9 \%$. Fuel meat swelling values are $54 \%$ for the peak and $28 \%$ for the average. A plot of fuel swelling versus local fission density in the fuel meat is shown in Figure 15. The dashed line in the plot at approximately 4.3E+21 fissions $/ \mathrm{cm}^{3}$ indicates the highest fission density that could be achieved using an LEU fuel of this type. The local fission density is determined using the gradient calculations described previously and includes the volume of matrix material within the fuel meat zone. The error bars shown indicate uncertainties in the physical measurements of the plates and fuel meat zones; however, larger uncertainties exist in the fuel loading (up to $25 \%$ variation), the subsequent calculated fission density values, and variations in the experiment test conditions.

\section{Fuel Meat Swelling vs Fission Density in Fuel Meat}

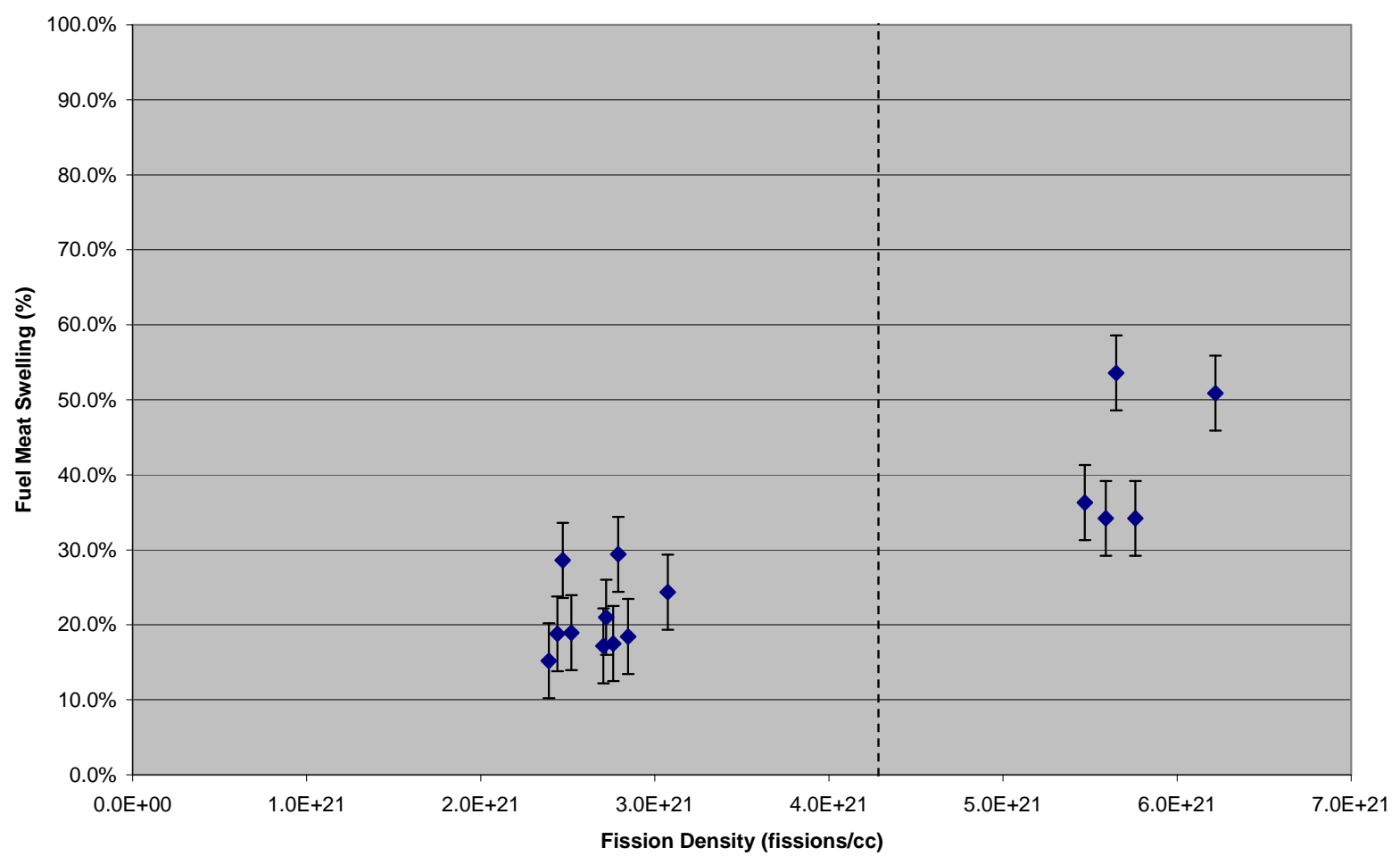

Figure 15. Plate R6R018 fuel swelling versus fission density. 


\subsection{Destructive Examinations}

Plate R6R018 was sectioned through the middle of the plate for metallographic examination. The cross section was mounted in epoxy, ground and polished to one micron polishing solution, and examined on an optical microscope. A montage of the cross section from this plate can be seen in Figure 16 with the higher fission density end to the right.

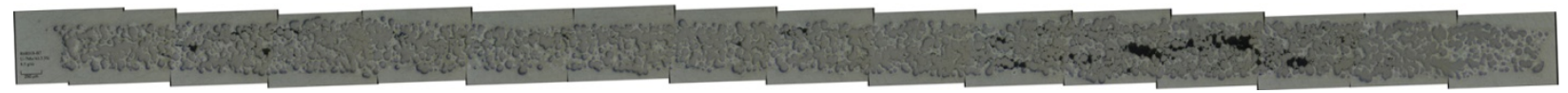

Figure 16. Cross section of Plate R6R018.

High magnification examination of the high power end of the plate $\left(7 \mathrm{E}+21\right.$ fissions $\left./ \mathrm{cm}^{3}\right)$ as compared to the lower power sections of the plate $\left(2.6 \mathrm{E}+21\right.$ fissions $\left./ \mathrm{cm}^{3}\right)$ (Figure 17), clearly shows the deformation and creep (toward the left) of the typically spherical fuel as outlined in previous literature due to the compressive stresses of the cladding at the edge of the plate. ${ }^{9}$ The compressive stresses in these regions also appear to have altered the fission gas behavior with the fuel particles retaining more fission gas internally and very little bubble formation on the particle periphery. There is also a visible interaction layer between the fuel particles and the cladding.

Further examination of the high power edge shows both porosity formation between the fuel and interaction layer as well as significant pullout due to sample preparation. Figure 18 (left) shows several spherical voids where large porosity (right) has led to fuel particles being removed during sample preparation.

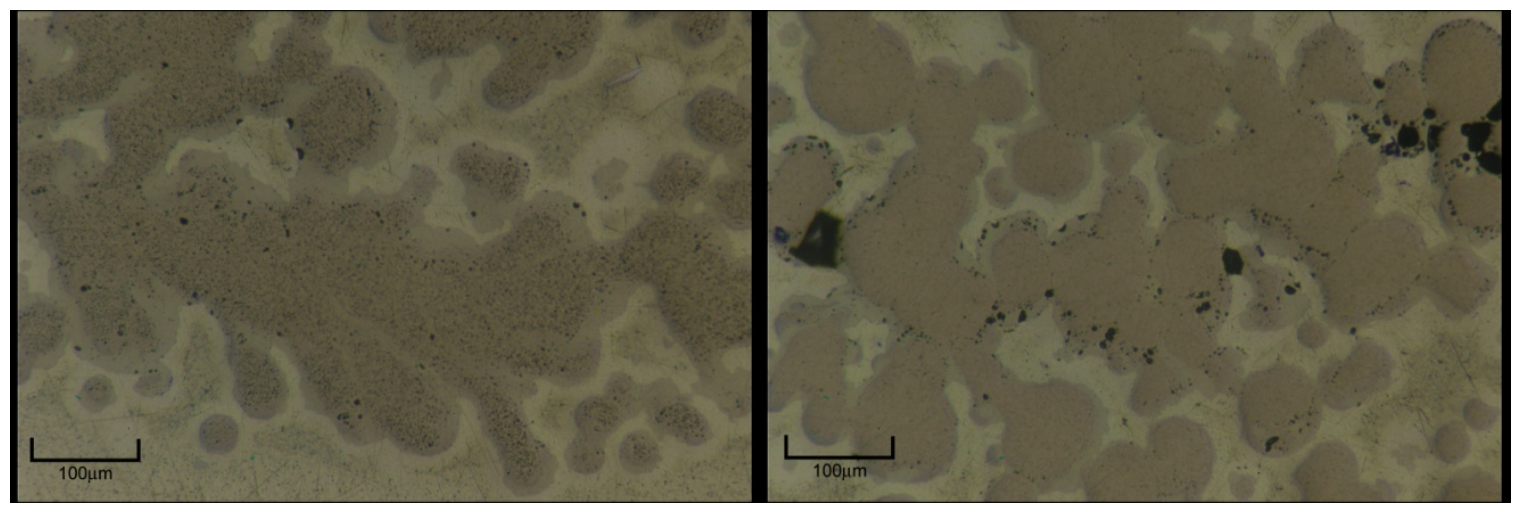

Figure 17. High magnification examination of the high power edge (left) and midpoint (right) of Plate R6R018.

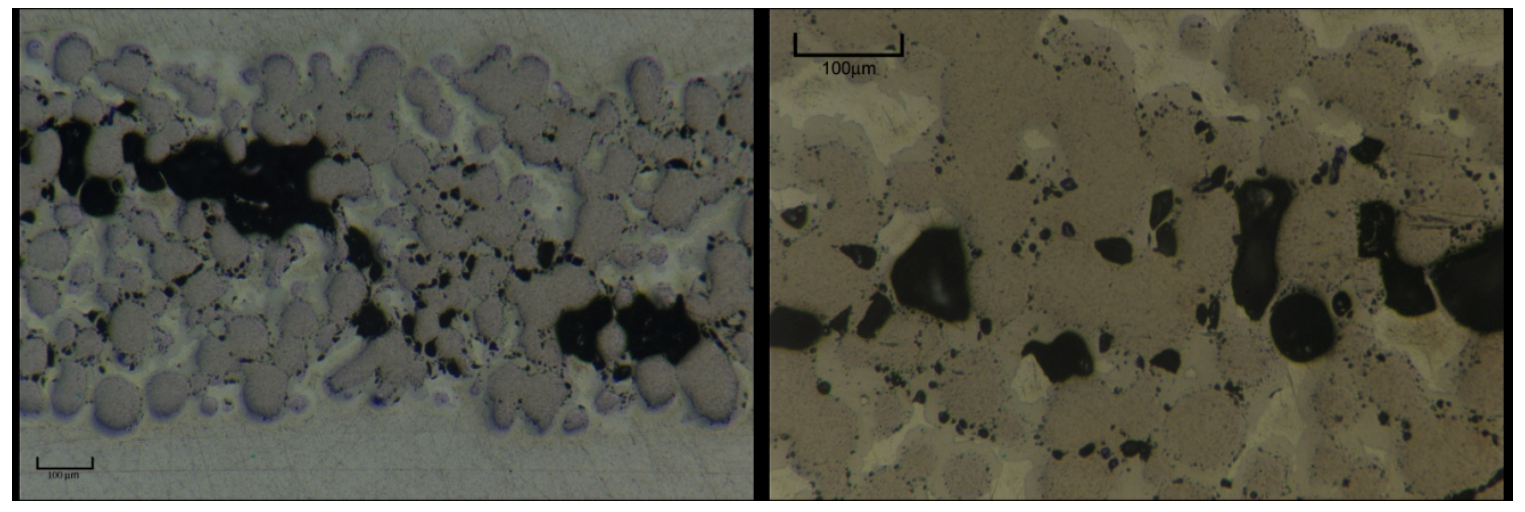

Figure 18. Metallographic images of the high power edge. 
Interaction layer formation between the fuel and matrix material appears to vary on the high power edge as shown in Figure 19. Areas where the silicon has been depleted from the matrix the reaction layer has grown thicker, 10-15 $\mu \mathrm{m}$ in thickness. In areas where the silicon is still present and has not been consumed, the reaction layers are thinner, 5-10 $\mu \mathrm{m}$ in thickness as predicted in the fuel performance modeling. The image to the left shows thicker regions where the silicon has depleted in the matrix while the image on the right shows thinner regions where silicon precipitates can still be seen in the matrix.

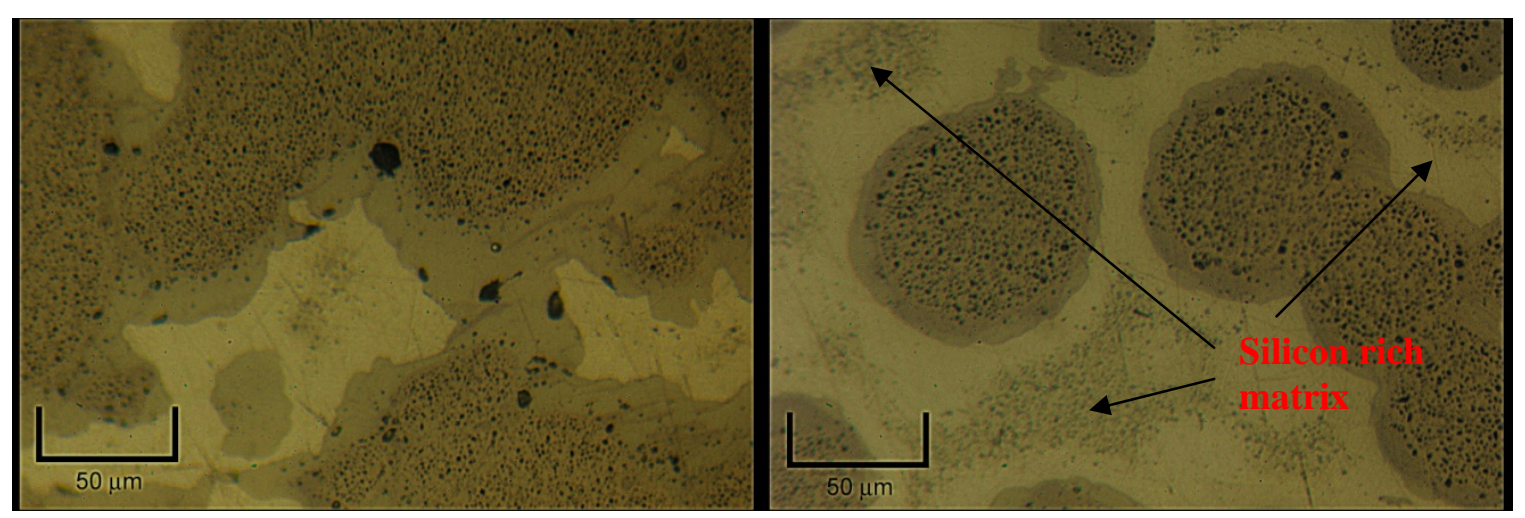

Figure 19. High magnification images of the high power edge of Plate R6R018.

Examination of the low power edge of the plate (Figure 20) shows relatively thin, uniform reaction layers on the order of 3-5 $\mu \mathrm{m}$ in thickness. These are similar to the thicknesses predicted by the fuel performance modeling and are close to the thicknesses seen in the as-fabricated sample indicating there was very little growth of the layer during irradiation. Some porosity can be seen beginning to form between the fuel and interaction layer. Pores are on the order of 1-2 $\mu \mathrm{m}$ in diameter.

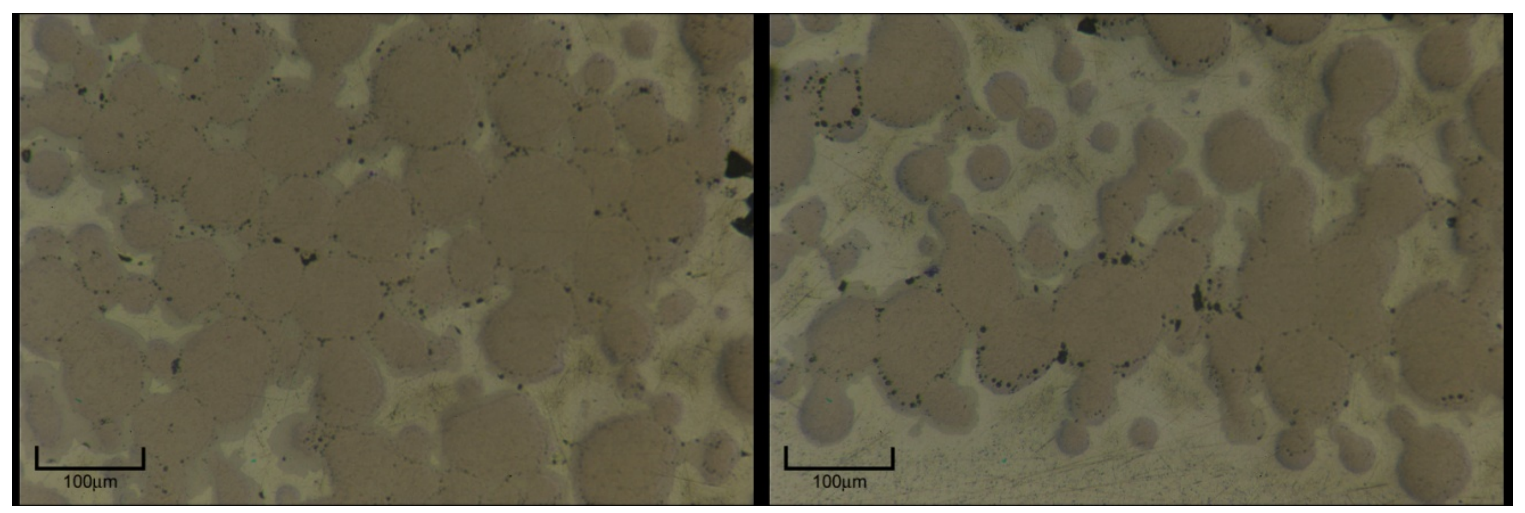

Figure 20. High magnification images of lower power edge of Plate R6R018. 


\section{DISCUSSION}

When examining the results from Plate R6R018, the predominate feature is the large variation in performance across the narrow 1-inch width of the plate. The fission rate and fission density gradient across this small area not only provides information about varying test conditions, but also introduces non-uniform stresses within the plate, which appear to significantly alter fuel performance.

Previous testing under similar conditions has regularly shown that the poorest performing regions of the fuel plates are not the most aggressively tested regions. Table 10 shows that the fission density at the edge of the plate is $\sim 30 \%$ higher than the fission density $3 \mathrm{~mm}$ into the fuel plate where significantly higher porosity is observed. This trend is thought to be a result of mechanical stresses exerted on the fuel.

As the highest burn-up fuel at the edge of the plate swells and subsequently creeps away from the edge of the plate, a peak swelling region is created approximately $1.5 \mathrm{~mm}$ from the edge of the fuel zone. As this peak region swells causing the cladding to bulge, the adjacent lower swelling region is then placed in tension due to the clad. The tension applied to that region of fuel zone appears to allow for significantly higher bubble formation and the appearance the fuel zone is tearing open.

This phenomenon has also been seen in regions where non-uniform fuel loading has led to non-uniform swelling. Adjacent regions placed in tension have not behaved as well as the overly loaded regions. If this mechanical stress is indeed the cause of excessive porosity, it would be expected that a more uniform behavior would be expected in plates without this large fission density gradient. 


\section{CONCLUSIONS}

The acceptable behavior of Plate R6R018 under aggressive test conditions indicates the viability of this fuel type in combination with sufficient silicon in the aluminum matrix that is available to prevent significant fuel/matrix interaction. The high fuel swelling values on the high power edge of the plate are in line with values expected at the very high fission densities achieved in these regions. 


\section{REFERENCES}

1 G. L Hofman, Y. S. Kim, A. B. Robinson, G. V. Shevlyakov, 2007, "Post Irradiation Analysis of RERTR-7A, 7B, and RERTR-8 Tests,” Proceedings of the 2007 International Meeting on Reduced Enrichment for Research and Test Reactors, Prague, Czech Republic, September 23-27, 2007.

2. J. F. Williams, 2007, "Experiment Test Plan for Reduced Enrichment for Research and Test Reactors Program RERTR-9B Fuel Plate Irradiation Tests in the ATR,” INL Experiment Test Plan, April 2007.

3. C. R. Clark, B. R. Muntifering, J. F. Jue, 2007, "Production and Characterization of Atomized U-Mo Powder by the Rotating Electrode Process,” Proceedings of the 2007 International Meeting on Reduced Enrichment for Research and Test Reactors, Prague, Czech Republic, September 23-27, 2007.

4. S. L. Hayes, G. L. Hofman, M. K. Meyer, J. Rest and J. L. Snelgrove, 2002, “Modeling of High Density U-Mo Dispersion Plate Performance," 2002 International Meeting on Reduced Enrichment for Research and Test Reactors, Bariloche, Argentina, November 3-8, 2002.

5. Yeon Soo Kim, G. L. Hofman, 2009, Revision of the U-Mo Fuel Swelling Correlation, ANL Intra-Laboratory Memo, January 15, 2009.

6. Yeon Soo Kim, G. L. Hofman, P. G. Medvedev, G. V. Shevlyakov, A. B. Robinson, H. J. Ryu, 2007 "Post Irradiation Analysis and Performance Modeling of Dispersion and Monolithic U-Mo Fuels," International Meeting on Reduced Enrichment for Research and Test Reactors, 2007 International Meeting on Reduced Enrichment for Research and Test Reactors, Prague, Czech, September 23-27, 2007.

7. G. S. Chang, M. A. Lillo, 2008, “As-Run Neutronics Analysis of the RERTR-9A/B Capsules in the ATR B-11 Position,” Engineering Calculations and Analysis Report -231, 2008.

8. G. S. Chang, M. A. Lillo, 2009, "MCNP-Calculated Gradients across RERTR-9 Miniplates Irradiated in ATR,” Engineering Calculations and Analysis Report-689, 2009.

9. G. L. Hofman, Y. S. Kim, A. B. Robinson, 2009, "Fission Induced Swelling and Creep of UraniumMolybdenum Alloy Fuel,” Proceedings of the 2009 Research Reactor Fuels Meeting, Vienna Austria, March 22-25, 2009. 